\title{
Balanço de nitrogênio, concentrações de ureia e síntese de proteína microbiana em caprinos alimentados com dietas contendo cana-de-açúcar tratada com óxido de cálcio ${ }^{1}$
}

\author{
Gleidson Giordano Pinto de Carvalho², Rasmo Garcia3,7, Aureliano José Vieira Pires4,7, \\ Robério Rodrigues Silva ${ }^{5}$, Mara Lúcia Albuquerque Pereira ${ }^{5}$, Pablo Teixeira Viana ${ }^{6}$, Alana \\ Batista dos Santos ${ }^{6}$, Taiala Cristina de Jesus Pereira ${ }^{6}$
}

\footnotetext{
1 Projeto financiado pela FAPESB.

2 Departamento de Produção Animal/UFBA, Salvador, BA.

${ }^{3}$ Departamento de Zootecnia/UFV, Viçosa, MG.

${ }^{4}$ Departamento de Tecnologia Rural e Animal/UESB, Itapetinga, BA.

${ }^{5}$ Departamento de Estudos Básicos e Instrumentais/UESB, Itapetinga, BA.

${ }^{6}$ Graduando em Zootecnia/UESB, Itapetinga, BA.

7 Pesquisador do CNPq.
}

RESUMO - Objetivou-se avaliar o efeito da hidrólise da cana-de-açúcar com óxido de cálcio (CaO) sobre o balanço de nitrogênio, as concentrações de ureia na urina e no plasma e a síntese na proteína microbiana em caprinos. Foram utilizados oito caprinos da raça Saanen, machos castrados, com peso corporal médio de 22,6 kg e 4 meses de idade, distribuídos em dois quadrados latinos $4 \times 4$, em quatro períodos experimentais de 14 dias. As rações, formuladas para ser isoproteicas, com $14 \%$ de proteína bruta (PB), foram compostas de $70 \%$ de cana-de-açúcar (tratada com $0 ; 0,75 ; 1,5$ ou 2,25\% de óxido de cálcio na matéria natural e corrigida com $1 \%$ de ureia) e 30\% de concentrado e fornecidas à vontade. A cana-de-açúcar com óxido de cálcio foi picada em desintegrador estacionário, pesada, acondicionada em baldes plásticos de 50 litros e tratada com o óxido de cálcio para ser fornecida aos animais após 24 horas de armazenamento. O balanço de nitrogênio, as concentrações de ureia na urina e no plasma e as excreções de ureia na urina não foram influenciadas pelo tratamento da cana-de-açúcar com óxido de cálcio. A concentração de alantoína (\% das purinas totais) foi maior e a de ácido úrico menor nas dietas com cana-de-açúcar hidrolisada com óxido de cálcio em relação à cana in natura. A produção e a eficiência microbiana não foram afetadas pela adição de óxido de cálcio à cana-de-açúcar em dietas para caprinos em crescimento.

Palavras-chave: cal, derivados de purinas, eficiência microbiana

\section{Nitrogen balance, urea concentrations and microbial protein synthesis in goats fed diets containing sugar cane treated with calcium oxide}

\footnotetext{
ABSTRACT - The objective of this work was to evaluate the effect of sugar cane hydrolysis with calcium oxide (CaO) on nitrogen balance, concetrations of urea in the urine and in the plasma and synthesis in microbial protein in goats. Eight castrated male Saanen breed goats, with $22.6 \mathrm{~kg}$ average body weight and at four months of age were used distributed in two $4 \times 4$ Latin squares, during four 14-day experimental periods. The rations which were formulated to be isoprotein, with $14 \%$ crude protein (CP) were composed of $70 \%$ sugar cane (treated with $0 ; 0.75 ; 1.5$ or $2.25 \%$ of calcium oxide in natural matter basis and corrected with $1 \%$ urea) and $30 \%$ of concentrate given ad libitum to animals. Sugar cane with calcium oxide was chopped in a stationary chopper, weighted and stored in 50-L plastic buckets and treated with calcium oxide to be given to the animals after 24 hours of storage. Nitrogen balance, urine and plasma urea concentrations and urine urea excretion were not affected by sugar cane +calcium oxide treatment. Concetration of allantoin (\% total purine) was higher and the uric acid concentration was lower in diets with sugar cane hidrolised with calcium oxide in relation to in natura sugar cane. The microbial production and efficiency are not affected by addition of calcium oxide to sugar cane in diets for growing goats.
}

Key Words: microbial efficiency, purine derivatives, rumination, whitewash 


\section{Introdução}

Em qualquer sistema de criação de animais ruminantes, em pastejo ou em confinamento, o consumo de alimentos é importante, pois determina o aporte de nutrientes para o atendimento das exigências de mantença e o desempenho animal (Detmann et al., 2003).

O custo com alimentação de animais ruminantes tem grande representatividade nos custos totais de produção. Assim, a busca de menor custo de produção em produtos de origem animal tem sido direcionada para a utilização racional de todos os recursos alimentares disponíveis, e o setor produtivo vem buscando alternativas alimentares de menor custo, como a utilização da cana-de-açúcar como volumoso para ruminantes.

Entre os componentes do alimento, a fração fibrosa é essencial em sistemas produção de animais em regiões tropicais, pois fornece quantidade significativa de energia a baixo custo (Detmann et al., 2007). Contudo, no tratamento de alimentos com elevadas concentrações de fibra de baixa digestibilidade, como a cana-de-açúcar (Prado \& Moreira, 2002; Mendonça et al., 2004a), tem-se indicado o uso de produtos químicos alcalinos, como o hidróxido de sódio e óxido de cálcio, que têm grande potencial. A adição desses produtos em volumosos tem como principal objetivo a hidrólise da fibra por meio da solubilização parcial da hemicelulose e expansão e ruptura das moléculas de celulose, aumentado a digestibilidade do alimento como um todo.

Neste contexto, os carboidratos são as principais fontes energéticas para o desenvolvimento dos microrganismos do rúmen e a taxa de produção microbiana pode ser modificada com a utilização de diferentes fontes ou com a aplicação de tratamentos.

Dessa forma, objetivou-se avaliar o efeito do tratamento da cana-de-açúcar com doses óxido de cálcio sobre o balanço de nitrogênio, as concentrações de ureia na urina e no plasma e a síntese de proteína microbiana em caprinos.

\section{Material e Métodos}

O experimento foi conduzido no Setor de Caprinocultura e no Laboratório de Forragicultura e Pastagens da Universidade Estadual do Sudoeste da Bahia, no Campus de Itapetinga, Bahia, utilizando-se oito cabritos da raça Saanen, machos castrados, com peso corporal médio inicial de 22,6 kg e 4 meses de idade, distribuídos em dois quadrados latinos $4 \times 4$.

Os animais foram mantidos em baias individuais com $1,2 \mathrm{~m}^{2}$ com piso ripado de madeira, providas de comedouros e bebedouros individuais. Os animais foram alimentados com dietas contendo $70 \%$ de cana-de-açúcar tratada com doses de 0; 0,75; 1,5 e 2,25\% de óxido de cálcio (CaO) e 30\% de concentrado. A cana-de-açúcar sem óxido de cálcio foi desintegrada e fornecida no momento do fornecimento das rações, enquanto a cana-de-açúcar hidrolisada foi pesada e acondicionada em baldes plásticos de 50 litros e adicionada com óxido de cálcio, sem diluição em água, e fornecida aos animais após 24 horas de armazenamento.

Tanto a cana sem óxido de cálcio ( $0 \%$ de $\mathrm{CaO})$ como aquela com 0,$75 ; 1,5$ e 2,25\% de óxido de cálcio foi adicionada de ureia (1,0\% da matéria natural) no momento do fornecimento aos animais, após diluição da ureia em água, na proporção de $1 \mathrm{~kg}$ de ureia para 4 litros de água. As dietas foram formuladas para conter nutrientes suficientes para ganho de peso de $0,2 \mathrm{~kg} / \mathrm{dia}$ (NRC, 2006). Não se adicionou fonte de enxofre à cana, uma vez que esse mineral já faz parte da mistura mineral utilizada (Tabela 1). As rações foram balanceadas para conter aproximadamente $14 \%$ de proteína bruta.

Durante todo o experimento, antes do fornecimento das rações (Tabela 2), determinou-se o teor de açúcares solúveis da cana-de-açúcar in natura e da cana hidrolisada com óxido de cálcio utilizando-se refratômetro; a média foi de $20,3^{\circ}$ Brix.

O experimento teve duração de 56 dias, divididos em quatro períodos de 14 dias: os dez primeiros dias de adaptação dos animais e os quatro dias finais de coleta de dados.

As rações foram fornecidas à vontade, duas vezes ao dia, às $7 \mathrm{~h}$ e às $15 \mathrm{~h}$, ajustadas de forma a manter as sobras em torno de 5 a $10 \%$ do fornecido, com água permanentemente à disposição dos animais. Durante todo o experimento, a quantidade de cana-de-açúcar e concentrado oferecidos foi registrada diariamente. No período de coleta, do $11^{\circ} \underline{a}$ ao $14^{\circ}$ dia de cada período experimental, amostras dos volumosos, do concentrado e das sobras de cada animal foram coletadas diariamente, acondicionadas em sacos plásticos e armazenadas em freezer para análises posteriores. Os

Tabela 1 - Composição dos ingredientes do concentrado e da dieta

\begin{tabular}{lcc}
\hline Ingrediente (\% na MS) & Concentrado & Dieta \\
\hline Cana de açúcar ${ }^{1}$ & - & 70,0 \\
Fubá de milho & 55,7 & 16,8 \\
Farelo de soja & 36,2 & 10,9 \\
Fosfato bicálcico & 2,3 & 0,7 \\
Mistura mineral ${ }^{2}$ & 5,8 & 1,6 \\
\hline${ }^{1}$ Cana-de-açúcar com (0, 0,75; 1,5 ou 2,25\% de óxido de cálcio na matéria natural) \\
e 1\% de ureia (\%MN).
\end{tabular}

R. Bras. Zootec., v.39, n.10, p.2253-2261, 2010 
animais foram pesados no início e ao final de cada período experimental, para estimativa das excreções de urina e nitrogênio ureico, em porcentagem do peso vivo.

Amostras dos volumosos e concentrado foram présecas em estufa com ventilação forçada a $60^{\circ} \mathrm{C}$ e processadas em moinho de faca com peneira de crivos de $1 \mathrm{~mm}$. Os teores de matéria seca (MS), matéria orgânica (MO), proteína bruta (PB), extrato etéreo (EE), fibra em detergente neutro (FDN), fibra em detergente ácido (FDA), proteína insolúvel em detergente neutro (PIDN), proteína insolúvel em detergente ácido (PIDA) e lignina $\left(\mathrm{H}_{2} \mathrm{SO}_{4} 72 \% \mathrm{p} / \mathrm{p}\right)$ foram obtidos seguindo os procedimentos citados por Silva \& Queiroz (2002) e o teor de fibra em detergente neutro corrigido para cinzas e proteína, segundo recomendações de Licitra et al. (1996) e Mertens (2002).

As estimativas dos teores de fibra em detergente neutro potencialmente digestível (FDNpD) e matéria seca potencialmente digestível (MSpD) dos alimentos foram obtidas conforme metodologias citadas por Paulino et al. (2006).

Os teores de carboidratos totais (CT) foram estimados segundo Sniffen et al. (1992): CT $=100-(\% \mathrm{~PB}+\% \mathrm{EE}+$

Tabela 2 - Composição das dietas experimentais

\begin{tabular}{|c|c|c|c|c|}
\hline & \multicolumn{4}{|c|}{$\begin{array}{c}\text { Óxido de cálcio na } \\
\text { cana-de-açúcar }^{1}\end{array}$} \\
\hline & 0 & 0,75 & 1,5 & 2,25 \\
\hline Matéria seca & 45,8 & 46,1 & 46,9 & 47,8 \\
\hline Matéria orgânica (\% MS) & 94,7 & 93,1 & 91,6 & 90,3 \\
\hline Proteína bruta (\% MS) & 14,8 & 14,8 & 14,7 & 14,9 \\
\hline PIDN (\% PB) & 17,2 & 16,1 & 15,8 & 18,7 \\
\hline PIDA (\% PB) & 7,3 & 8,9 & 6,7 & 7,7 \\
\hline Extrato etéreo (\% MS) & 2,4 & 2,5 & 2,1 & 2,0 \\
\hline Cinzas (\% MS) & 5,3 & 6,9 & 8,4 & 9,7 \\
\hline Carboidratos totais (\% MS) & 75,4 & 74,4 & 73,3 & 72,1 \\
\hline Fibra em detergente neutro (\% MS) & 43,7 & 45,0 & 42,2 & 39,6 \\
\hline FDNcp (\% MS) & 39,5 & 41,0 & 37,8 & 35,1 \\
\hline FDNi (\% MS) & 22,4 & 23,1 & 19,9 & 16,8 \\
\hline FDNpd & 21,3 & 21,9 & 22,3 & 22,9 \\
\hline Carboidratos não-fibrosos (\% MS) & 31,6 & 29,4 & 31,1 & 32,5 \\
\hline CNFcp (\% MS) & 35,8 & 33,4 & 35,5 & 37,0 \\
\hline Fibra em detergente ácido (\% MS) & 28,4 & 29,7 & 26,5 & 26,2 \\
\hline FDAi (\% MS) & 18,1 & 17,8 & 17,4 & 12,9 \\
\hline Hemicelulose (\% MS) & 15,3 & 15,3 & 15,7 & 13,5 \\
\hline Celulose (\% MS) & 24,0 & 24,4 & 21,9 & 21,8 \\
\hline Lignina (\% MS) & 5,4 & 5,3 & 4,6 & 4,3 \\
\hline MSpD (\% MS) & 78,8 & 78,2 & 81,2 & 84,3 \\
\hline Matéria seca indigestível (\% MS) & 25,4 & 26,5 & 22,8 & 19,6 \\
\hline $\begin{array}{l}\text { Nutrientes digestíveis } \\
\text { totais }(\% \mathrm{MS})^{2}\end{array}$ & 64,3 & 62,7 & 63,0 & 62,8 \\
\hline
\end{tabular}

${ }^{1}$ Cana-de-açúcar adicionada de 1\% de ureia e doses de óxido de cálcio aplicadas, em \% da matéria natural.

2 Estimado segundo NRC (2001).

PIDN = proteína insolúvel em detergente neutro; PIDA = proteína insolúvel em detergente ácido; FDNcp = fibra em detergente neutro corrigida para cinzas e proteína; $\mathrm{FDNi}$ = fibra em detergente neutro indigestível; FDNpd = fibra em detergente neutro potencialmente digestível; $\mathrm{CNFcp}=$ carboidratos não-fibrosos corrigidos para cinzas e proteína; FDAi = fibra em detergente ácido indigestível; $\mathrm{MSpD}=$ matéria seca potencialmente digestível. \%cinzas) e os de carboidratos não-fibrosos corrigidos para cinzas e proteína (CNFcp), conforme equação proposta por Hall (2003):

$$
\mathrm{CNF} c \mathrm{p}=(100-\% \mathrm{FDNcp}-\% \mathrm{~PB}-\% \mathrm{EE}-\% \text { cinzas }) \text {. }
$$

Os nutrientes digestíveis totais (NDT) foram calculados segundo Weiss (1999), porém utilizando a fibra em detergente neutro e os carboidratos não-fibrosos corrigidos para cinzas e proteína, pela seguinte equação:

NDT $(\%)=$ PBD + FDNcpD + CNFcpD + 2,25EED .

em que: $\mathrm{PBD}=\mathrm{PB}$ digestível; $\mathrm{FDNcpD}=\mathrm{FDNcp}$ digestível; $\mathrm{CNF} c \mathrm{D}=\mathrm{CNF}$ cp digestíveis; e EED = EE digestível.

Os teores de nutrientes digestíveis totais estimados (NDTest) dos alimentos e das rações foram obtidos conforme equações descritas pelo NRC (2001). Na estimativa dos nutrientes digestíveis totais estimado da cana-de-açúcar, utilizou-se a equação: NDTest $=0,98$ [100 $-(\% \mathrm{FDNp}+\% \mathrm{~PB}+\% \mathrm{EE}+\%$ cinza $)] \times \mathrm{PF}+\mathrm{PB} \times \exp [-1,2$ $\times(\mathrm{PIDA} / \mathrm{PB})]+2,25 \times(\mathrm{EE}-1)+0,75 \times(\mathrm{FDNp}-$ Lignina $) \times$ [1 - (Lignina/FDNp $\left.)^{0,667}\right]-7$ e, para o cálculo do NDTest do concentrados, a equação: NDTest $=0,98$ [100 $-(\%$ FDNp $+\% \mathrm{~PB}+\% \mathrm{EE}+\%$ cinza $)] \times \mathrm{PF}+\mathrm{PB} \times \exp [-0,4 \times(\mathrm{PIDA} /$ $\mathrm{PB})]+2,25 \times(\mathrm{EE}-1)+0,75 \times(\mathrm{FDNp}-$ lignina $) \times[1$ - (lignina/ FDNp $\left.)^{0,667}\right]-7$, em que: $F D N p=F D N \times P I D N$, em que: PIDN = nitrogênio insolúvel em detergente neutro 6,25 e $\mathrm{PF}=$ efeito do processamento físico na digestibilidade dos carboidratos não-fibrosos; PIDA = nitrogênio insolúvel em detergente ácido $\times 6,25$ para valores de $\mathrm{EE}<1$, na equação $(E E-1)=0$.

Na estimação dos teores de matéria seca indigestível e fibra em detergente neutro indigestível das rações, amostras dos alimentos fornecidos (cana e concentrado) foram incubadas por 240 horas (Casali et al., 2008) em duplicata (20 mg MS/ $/ \mathrm{cm}^{2}$ ) em sacos de náilon, não resinado (TNT - $100 \mathrm{~g} / \mathrm{m}^{2}$ ) no rúmen de dois novilhos mestiços recebendo dieta mista. Após esse período, os sacos foram retirados, lavados em água corrente, e o material remanescente da incubação foi colocado em estufa com ventilação forçada e com temperatura controlada a $60^{\circ} \mathrm{C}$ por 72 horas. A matéria seca considerada indigestível foi obtida em estufa a $105^{\circ} \mathrm{C}$ por 24 horas. Prosseguindo, os sacos foram, então, acondicionados em potes plásticos, adicionados $50 \mathrm{~mL}$ de detergente neutro por saco, e submetidos à fervura em detergente neutro por uma hora, sendo em seguida lavados com água quente e acetona, secos a $65^{\circ} \mathrm{C}$ e pesados. Em seguida os sacos foram abertos e amostras submetidas a secagem em estufa a $105^{\circ} \mathrm{C}$, conforme o procedimento anterior, sendo o novo resíduo considerado como fibra em detergente neutro indigestível. 
A coleta total de fezes foi feita do $11^{\circ}$ ao $14^{\circ}$ dia de cada período experimental. A coleta efetuada em cada período, por animal, foi realizada com o auxílio de uma tela de polietileno, instalada na parte inferior de cada baia e coletor de urina adaptado aos animais para que não houvesse contaminação. As fezes foram pesadas pela manhã, e retirado aproximadamente $10 \%$ do total, o qual foi congelado em freezer a $-10^{\circ} \mathrm{C}$ para posteriores análises.

No $14^{\circ}$ dia de cada período experimental, foram realizadas coletas de urina, spot, em micção espontânea dos animais, aproximadamente quatro horas após o fornecimento da alimentação matinal. As amostras foram filtradas em gaze e uma alíquota de $10 \mathrm{~mL}$ foi separada e diluída com $40 \mathrm{~mL}$ de ácido sulfúrico (0,036 N) (Valadares et al., 1999), a qual foi destinada à quantificação das concentrações de ureia, nitrogênio, creatinina, alantoína, ácido úrico, xantina e hipoxantina na urina.

Ao final do quarto período experimental, os animais foram alocados em gaiolas para estudo de metabolismo para a coleta total de urina. Em cada animal, foi adaptada uma sacola de napa para evitar a contaminação da urina com fezes. Baldes plásticos cobertos com telas, contendo $20 \mathrm{~mL}$ de $\mathrm{HCl}$ (1:1) para evitar a volatilização de nitrogênio e possível deterioração foram inseridos embaixo das gaiolas para aparar a urina, sendo a coleta realizada sempre no mesmo horário, pela manhã, durante quatro dias ininterruptos. Para estimar a excreção diária total de creatinina o volume total de urina foi pesado e o volume medido em proveta graduada com capacidade de 1 litro, todos os dias, dos quais amostras de $10 \%$ do total foram acondicionadas em potes plásticos de $100 \mathrm{~mL}$, devidamente identificados por animal, e armazenadas em freezer para posterior análise de creatinina.

A excreção diária de creatinina (mg/kg de PV) foi, portanto, obtida nos próprios animais do experimento, como: $\operatorname{ECCT~}(\mathrm{mg} / \mathrm{L}) \times \mathrm{VU}(\mathrm{L}) / \mathrm{PV}(\mathrm{kg})$; em que: ECCT = excreção de creatinina $(\mathrm{mg} / \mathrm{L})$ na amostra de urina (coleta total); VU = o volume urinário médio obtido nos quatro dias de coleta de urina; $\mathrm{PV}=$ peso vivo do animal $(\mathrm{kg})$.

Esse valor de excreção de creatinina, obtido na coleta total de urina, foi utilizado para estimar o volume urinário dos animais por meio da avaliação da concentração de creatinina nas amostras de urina spot. O volume urinário, por sua vez, foi utilizado no cálculo das excreções de nittrogênio, ureia e derivados de purinas na urina, conforme será discutido posteriormente.

O volume urinário utilizado para estimar a excreção diária de purinas totais (PT) das amostras de urina spots foi obtido, para cada animal, nos diferentes tratamentos, dividindo-se o a excreção de creatinina obtida no procedimento anterior da coleta total $(\mathrm{mg} / \mathrm{kg}$ PV) pela concentração média de creatinina $(\mathrm{mg} / \mathrm{dL})$ na amostra spot de urina, multiplicando-se o resultado pelo respectivo PV do animal.

A coleta de sangue foi realizada na veia jugular, no $14^{\circ}$ dia, aproximadamente quatro horas após o fornecimento da alimentação da manhã, utilizando-se tubos (VacutainerTM) de $5 \mathrm{~mL}$ com ácido etilenodiamino tetraacético (EDTA). Em seguida, as amostras de sangue foram transferidas para o laboratório, centrifugadas a $3.500 \mathrm{rpm}$ por 10 minutos e o plasma acondicionado em eppendorfs e colocados em freezer a $-20^{\circ} \mathrm{C}$ até a realização das análises.

As concentrações de creatinina e ácido úrico na urina e ureia na urina e no plasma foram estimadas utilizando-se kits comerciais (Bioclin). A conversão dos valores de ureia em nitrogênio ureico foi realizada pela multiplicação dos valores obtidos pelo fator 0,4667 . Os teores urinários de alantoína, ácido úrico, xantina e hipoxantina foram estimados por intermédio de métodos colorimétricos, conforme especificações de Chen \& Gomes (1992), sendo o teor de nitrogênio total estimado pelo método de Kjeldhal (Silva \& Queiroz, 2002).

O balanço de nitrogênio ( $\mathrm{N}$-retido, g/dia) foi calculado com: $\mathrm{N}$-retido $=\mathrm{N}$ ingerido $(\mathrm{g})-\mathrm{N}$ nas fezes $(\mathrm{g})-\mathrm{N}$ na urina $(\mathrm{g})$.

A excreção de purinas totais (PT) foi estimada pela soma das quantidades de alantoína, ácido úrico, xantina e hipoxantina excretadas na urina. A quantidade de purinas microbianas absorvidas ( $\mathrm{mmol} / \mathrm{dia}$ ) foi estimada a partir da excreção de purinas totais (mmol/dia), por meio da equação proposta por Belenguer et al. (2002) para caprinos: $\mathrm{PA}(\mathrm{mmol} / \mathrm{dia})=\mathrm{PT} / 0,76$, em que: $\mathrm{PA}=$ purinas absorvidas (mmol/dia); PT $=$ excreção de purinas totais (mmol/dia) e o valor de 0,76 corresponde à taxa de recuperação das purinas.

O fluxo intestinal de nitrogênio microbiano (g NM/ dia) foi estimado a partir da quantidade de purinas absorvidas (mmol/dia), segundo a equação: $\mathrm{NM}(\mathrm{g} /$ dia $)=\mathrm{PA} /(0,92 \times 1,97)$, na qual Belenguer et al. (2002) assumiram que 0,92 é a digestibilidade verdadeira das bases purinas no duodeno e 1,97 (mmol de bases purinas/g nitrogênio) a razão entre as bases purinas e o conteúdo de nitrogênio na população microbiana extraída do rúmen de caprinos.

Nas análises estatísticas dos resultados, procedeu-se à decomposição da soma de quadrados relacionada às doses de óxido de cálcio na cana-de-açúcar, por meio de contrastes ortogonais (Tabela 3). Ao primeiro contraste (A) atribuiu-se a comparação entre as médias da cana-de-açúcar controle (cana in natura) e das dietas com cana-de-açúcar com óxido de cálcio. Os contrastes representados pelas 
Tabela 3 - Distribuição dos coeficientes para os contrastes ortogonais empregados na decomposição da soma de quadrados para tratamentos

\begin{tabular}{lcccc}
\hline \multicolumn{5}{c}{ Coeficiente } \\
\hline Contraste & $\begin{array}{c}\text { Cana-de-açúcar } \\
\text { in natura }\end{array}$ & 0,75 & 1,5 & 2,25 \\
\hline $\mathrm{A}$ & +3 & -1 & -1 & -1 \\
$\mathrm{~B}$ & 0 & -1 & 0 & +1 \\
$\mathrm{C}$ & 0 & -1 & +2 & -1 \\
\hline
\end{tabular}

letras B e C permitiram a avaliação de efeitos de ordem linear e quadrática das doses de óxido de cálcio na cana-deaçúcar, respectivamente. Os procedimentos estatísticos foram realizados com o auxílio do programa SAS (Statistical Analisys System) adotando-se 0,05 como nível crítico de probabilidade.

\section{Resultados e Discussão}

As doses de óxido de cálcio na cana-de-açúcar não influenciaram a excreção de creatinina, que foi em média $16,33 \mathrm{mg} / \mathrm{kg}$ de peso vivo. O maior valor de nitrogênio ingerido e excretado nas fezes foi obtido com as dietas com cana-de-açúcar com óxido de cálcio (Tabela 4). Os consumos de nitrogênio e nitrogênio digerido (g/dia) aumentaram de forma linear $(\mathrm{P}<0,05)$ de acordo com as doses de óxido de cálcio na cana-de-açúcar.

A maior ingestão de nitrogênio no grupo alimentado com cana hidrolisada com óxido de cálcio em relação à cana in natura refletiu na excreção de nitrogênio nas fezes, que foi maior $(\mathrm{P}<0,01)$ na cana com óxido de cálcio. Do mesmo modo, é possível que o consumo de nitrogênio também tenha ocasionado aumento do nitrogênio digerido (Tabela 4), pois foram observados valores de 17,3; 18,0 e 20,3 g/dia, respectivamente, para as doses de 0,$75 ; 1,5$ e 2,25\% de óxido de cálcio na cana-de-açúcar. Esses valores, entretanto, são superiores aos observados por Branco et al. (2003), que relataram 4,7; 5,6; 6,2; 7,1 e 7,6 g/dia, respectivamente, para as substituições de farelo de soja por farinha de pena de $0,25,50,75$ e $100 \%$ em dietas para ovinos. De forma semelhante a este trabalho, esses autores também observaram aumento nos consumos de nitrogênio, que refletiram na excreção de nitrogênio nas fezes.

As excreções urinárias de nitrogênio não foram afetadas $(\mathrm{P}>0,05)$ pelas doses de óxido de cálcio na canade-açúcar e também foram próximas aos valores relatados por Branco et al. (2003) para ovinos, que registraram valores de 16,3;15,8; 14,7; 14,8 e 13,9 g/dia, respectivamente, para as substituições de farelo de soja por farinha de pena de 0 , $25,50,75$ e $100 \%$.

O teor de nitrogênio retido, em suas diferentes formas de expressão, não foi influenciado $(\mathrm{P}>0,05)$ pelas doses de óxido de cálcio. A retenção de nitrogênio foi de 5,5; 5,3; 6,2 e 7,0 g/dia, respectivamente, para as dietas com cana in natura e com cana hidrolisada com 0,75; 1,5 e 2,25\% de óxido de cálcio. Esses valores estão de acordo com os obtidos por Moraes (2007) em caprinos em crescimento. Esses autores relataram valores de 3,0; 4,7; 4,5 e 5,9 g/dia, respectivamente, para dietas contendo $18,36,46$ e $72 \%$ de urucum (\%MN) e valores de 6,1; 5,6; 6,6 e 5,7 g/dia, respectivamente, para dietas contendo 10, 15, 20 e 25\% de farelo de castanha. Embora neste estudo tenha-se utilizado ureia como fonte de nitrogênio não-proteico, os teores de proteína das dietas foram próximos aos relatados pelos autores e os animais também foram caprinos em crescimento, machos, com peso vivo semelhante ao usado neste estudo.

Em estudo realizado por Mouro et al. (2007), os autores avaliaram a influência de duas fontes de carboidratos (casca de soja e milho grão) e dois níveis de volumoso (40 e 70\%) em dietas para ovinos e, assim como neste trabalho, não observaram efeito das dietas sobre a retenção de nitrogênio,

Tabela 4 - Médias de quadrados mínimos do balanço de nitrogênio em caprinos alimentados com dietas contendo cana-de-açúcar in natura ou tratada com óxido de cálcio

\begin{tabular}{|c|c|c|c|c|c|c|c|c|}
\hline \multirow[t]{2}{*}{ Item } & \multicolumn{4}{|c|}{ Dose de óxido de cálcio } & \multirow[b]{2}{*}{ CV (\%) } & \multicolumn{3}{|c|}{ Efeito $^{1}$} \\
\hline & $\begin{array}{c}\text { Cana } \\
\text { in natura }\end{array}$ & 0,75 & 1,5 & 2,25 & & $\begin{array}{c}\text { Controle } \times \\
\text { óxido de cálcio }\end{array}$ & Linear & Quadrático \\
\hline Nitrogênio ingerido $(\mathrm{g} / \mathrm{dia})^{2}$ & 23,0 & 23,6 & 25,1 & 27,8 & 11,2 & $*$ & $* *$ & ns \\
\hline Nitrogênio nas fezes (g/dia) & 5,5 & 6,3 & 7,1 & 7,4 & 18,6 & $* *$ & ns & ns \\
\hline Nitrogênio digerido $(\mathrm{g} / \mathrm{dia})^{3}$ & 17,4 & 17,3 & 18,0 & 20,3 & 11,2 & ns & $* *$ & ns \\
\hline Nitrogênio digerido (\% do ingerido) & 76,1 & 73,2 & 71,5 & 73,2 & 4,7 & $*$ & ns & ns \\
\hline N-urina (g/dia) & 12,0 & 12,0 & 11,8 & 13,3 & 15,5 & ns & ns & ns \\
\hline N-retido (g/dia) & 5,5 & 5,3 & 6,2 & 7,0 & 32,3 & ns & ns & ns \\
\hline Nitrogênio retido (\% do ingerido) & 23,3 & 21,8 & 23,9 & 25,1 & 26,2 & ns & ns & ns \\
\hline Nitrogênio retido (\% do digerido) & 30,8 & 29,6 & 33,3 & 34,2 & 27,8 & ns & ns & ns \\
\hline
\end{tabular}

1 (ns), $\left({ }^{*}\right)$ e $(* *)$ : não-significativo $(\mathrm{P}>0,05)$ e significativo a 0,05 e 0,01 de probabilidade, respectivamente.

$2 \hat{\mathrm{Y}}=21,3902+2,74651 \mathrm{X}\left(\mathrm{r}^{2}=0,9731\right) .{ }^{3} \hat{\mathrm{Y}}=15,5627+1,99298 \mathrm{X}\left(\mathrm{r}^{2}=0,9067\right)$.

$\mathrm{CV}=$ coeficiente de variação. 
cujo valor médio foi de 5,72 g/dia, próximo da média de $6 \mathrm{~g} /$ dia verificada neste trabalho. Entretanto, três das quatro dietas avaliadas pelos autores foram balanceadas utilizando também a ureia com uma das fontes de nitrogênio.

As concentrações de nitrogênio ureico na urina e no plasma e as excreções diárias de ureia e nitrogênio ureico na urina não foram influenciadas $(\mathrm{P}>0,05)$ pela utilização de óxido de cálcio no tratamento químico da cana-de-açúcar (Tabela 5).

A concentração plasmática de nitrogênio ureico em ruminantes está diretamente relacionada ao consumo de proteína e tem sido usada em estudos para verificar o estado nutricional proteico dos animais (Barton et al., 1996; Butler et al., 1996; Butler, 1998; Ruas et al., 2000). Nas concentrações plasmáticas de nitrogênio ureico apresentados neste estudo, 23,6; 24,7; 26,2 e 26,8 mg/dL, respectivamente, nas doses de $0 ; 0,75 ; 1,5$ e 2,25\% de óxido de cálcio, o teor proteico usado nas rações foi suficiente para atender a demanda de nitrogênio dos animais. Estudos avaliando as concentrações de nitrogênio em caprinos são escassos, porém os valores apresentados neste estudo estão de acordo com os observados na literatura para bovinos em crescimento (Magalhães et al., 2005) e em lactação (Oliveira et al., 2001; Pina et al., 2006).

Dos compostos nitrogenados que chegam ao rúmen, cerca de 50 a 70\% são degradados pelos microrganismos, liberando amônia. Durante a fermentação ruminal, sempre que excede o nível de utilização pelos microrganismos ruminais, a concentração de amônia é obsorvida e, por meio da circulação entero-hepática, chega ao fígado, onde é transformada em ureia, que, juntamente com a ureia produzida no fígado a partir do metabolismo de aminoácidos, constitui a maior parte da ureia plasmática. Parte dessa ureia é reciclada, via saliva e parede ruminal, e volta para o rúmen e a outra é excretada pela urina (Kozloski, 2002). Por intermédio da união dessas informações, é possível pressupor que, como as fontes e os teores proteicos das dietas foram os mesmos, nenhuma diferença foi encontrada para as concentrações de nitrogênio ureico na urina e no plasma e para as excreções de nitrogênio ureico e ureia na urina neste estudo.

As excreções de alantoína, ácido úrico, xantina e hipoxantina e purinas totais e as purinas microbianas absorvidas não foram influenciadas $(\mathrm{P}>0,05)$ pelas doses de óxido de cálcio utilizadas no tratamento químico da canade-açúcar (Tabela 6). Ressalta-se, entretanto, que houve efeito para o contraste cana-de-açúcar in natura vs. canade-açúcar com óxido de cálcio (Tabela 6) para a alantoína e o ácido úrico (\% purinas totais), de modo que o maior valor de alantoína $(\mathrm{P}<0,05)$ e o menor de ácido úrico $(\mathrm{P}<0,01)$ no grupo com cana-de-açúcar tratada com óxido de cálcio.

Os valores de derivados de purinas (alantoína, ácido úrico, xantina e hipoxantina) observados neste estudo estão de acordo com os relatados por Fonseca et al. (2006), em pesquisa na qual avaliaram dietas contendo diferentes níveis de proteína bruta (11,5; 13,5; 15,5 e 17,5\%) para caprinos. Entre outras variáveis que estão de acordo com os resultados observados pelos autores, pode-se citar a excreção de alantoína, que representou mais de $80 \%$ das purinas totais, como observado por Fonseca et al. (2006), que relataram valores de 85,2 e $80,6 \%$, respectivamente, para dietas contendo 11,5 e 13,5\% de proteína para caprinos.

Valores superiores aos obtidos neste estudo têm sido comumente observados na literatura para bovinos, conforme pode ser observado nos experimentos de Oliveira et al. (2001), Mendonça et al. (2004b) e Pina et al. (2006), em que a excreção de alantoína representou 87,8; 91,8 e 89,1\%, respectivamente, do total de derivados de purinas excretadas. Isso se deve ao fato de os bovinos excretarem exclusivamente ácido úrico e alantoína, pois, segundo Chen \& Gomes (1992), a grande atividade da enzima xantina

Tabela 5 - Médias de quadrados mínimos das concentrações de N-ureico e ureia em caprinos alimentados com dietas contendo canade-açúcar in natura ou tratada com óxido de cálcio

\begin{tabular}{|c|c|c|c|c|c|c|c|c|}
\hline \multirow[t]{2}{*}{ Item } & \multicolumn{4}{|c|}{ Dose de óxido de cálcio (\% MN) } & \multirow[b]{2}{*}{ CV (\%) } & \multicolumn{3}{|c|}{ Efeito $^{1}$} \\
\hline & $\begin{array}{c}\text { Cana } \\
\text { in natura }\end{array}$ & 0,75 & 1,5 & 2,25 & & $\begin{array}{l}\text { Cana-de-açúcar × } \\
\text { óxido de cálcio }\end{array}$ & Linear & Quadrático \\
\hline \multicolumn{9}{|c|}{ Concentrações (mg/dL) } \\
\hline N-ureico na urina & 595,4 & 644,4 & 624,5 & 609,7 & 16,0 & ns & ns & ns \\
\hline \multicolumn{9}{|c|}{ Excreções (g/dia) } \\
\hline Ureia na urina & 10,0 & 9,6 & 10,2 & 10,7 & 27,1 & ns & ns & ns \\
\hline N-ureico na urina & 4,5 & 4,3 & 4,5 & 4,6 & 26,5 & ns & ns & ns \\
\hline \multicolumn{9}{|c|}{ Excreções (mg/kg PV) } \\
\hline N-ureico na urina & 179,5 & 171,1 & 181,7 & 187,2 & 25,8 & ns & ns & ns \\
\hline
\end{tabular}

${ }^{1} \mathrm{~ns}=$ não-significativo $(\mathrm{P}>0,05)$.

$\mathrm{MN}=$ matéria natural; $\mathrm{CV}=$ coeficiente de variação. 
oxidase no sangue e nos tecidos desses animais, converte xantina e hipoxantina a ácido úrico, antes da excreção. A maior parte desse ácido úrico, entretanto, é degradada ao produto principal de excreção, alantoína, pela ação da uricase (Leningher et al., 1995), como ocorre na maioria dos mamíferos.

Segundo Yu et al. (2002), entre outros fatores, as excreções de alantoína, ácido úrico, xantina e hipoxantina podem ser afetadas pelas fontes de proteína dietética e energia, pelo peso vivo, pelos aditivos alimentares e pela espécie. Essa informação é condizente com os resultados observados, pois a ausência de efeito significativo pode estar relacionada à similaridade entre as fontes alimentares e o peso dos animais (caprinos Sannen em crescimento) utilizados no experimento. Evidentemente que essas pressuposições estão amplamente relacionadas à falta de efeito do aditivo químico óxido de cálcio utilizado no tratamento da cana-de-açúcar, o qual não teve efeito significativo sobre as excreções diárias de derivados de purinas.

A produção microbiana seguiu o mesmo comportamento observado nas excreções de alantoína e purinas totais, ou seja, não apresentou efeito significativo do tratamento da cana-de-açúcar com óxido de cálcio ( $\mathrm{P}>0,05)$, o que está de acordo com as observações de Puchala \& Kulasek (1992) em ovinos e Fonseca et al. (2006) em caprinos. De acordo com esses autores, esse comportamento indica alta correlação entre excreção de derivados de purinas na urina e fluxo de compostos nitrogenados microbianos no duodeno.
As estimativas de síntese de compostos nitrogenados microbianos observadas neste estudo, de 5,42; 5,52; 5,95 e $5,72 \mathrm{~g} /$ dia, respectivamente, nas doses de $0 ; 0,75 ; 1,5 \mathrm{e}$ 2,25\% de óxido de cálcio, foram inferiores aos valores relatados por Fonseca et al. (2006), que observaram valores de 13,3 a 17,3 g/dia, e próximas aos obtidos por SotoNavarro et al. (2003), que registraram fluxo de nitrogênio microbiano de 6,0 a 8,8 g/dia.

Os resultados de eficiência microbiana (em g PB/kg NDT) observados neste experimento não foram afetados ( $\mathrm{P}>0,05)$ pelas doses de óxido e cálcio na cana-de-açúcar e situaram-se entre 55,8 e 66,7 g PB/kg NDT, semelhante aos resultados observados por Fonseca et al. (2006) para caprinos, que, ao estimarem a eficiência da síntese microbiana em caprinos por meio das técnicas das bases púricas no omaso e da excreção de derivados de purinas, a partir da coleta total de urina ou da coleta spot, registraram valores de 60,7; 64,1; 63,9 e 67,4 g PB/kg NDT, respectivamente, nos níveis de 11,5; 13,5; 15,5 e 17,5\% de proteína bruta na dieta dos animais. Entretanto, esses valores observados pelos autores foram obtidos a partir da coleta spot de urina e os valores de purinas microbianas absorvidas utilizados para obter as eficiências foram estimados pela equação proposta por Belenguer et al. (2002), procedimento também adotado neste estudo. Os valores de eficiência de síntese microbiana apresentados neste estudo não têm relação alguma com o valor de 130 g PB/kg NDT preconizado pelo NRC (2001).

Tabela 6 - Síntese de proteína microbiana em caprinos alimentados com dietas contendo cana-de-açúcar in natura ou tratada com óxido de cálcio

\begin{tabular}{|c|c|c|c|c|c|c|c|c|}
\hline \multirow[t]{2}{*}{ Item } & \multicolumn{4}{|c|}{ Dose de óxido de cálcio (\% MN) } & \multirow[b]{2}{*}{ CV (\%) } & \multicolumn{3}{|c|}{ Efeito $^{1}$} \\
\hline & $\begin{array}{c}\text { Cana } \\
\text { in natura }\end{array}$ & 0,75 & 1,5 & 2,25 & & $\begin{array}{c}\text { Cana-de-açucar vs. } \\
\text { óxido de cálcio }\end{array}$ & Linear & Quadrático \\
\hline \multicolumn{9}{|c|}{ Excreções urinárias (mmol/dia) } \\
\hline Alantoína & 6,10 & 6,41 & 6,96 & 6,74 & 21,8 & ns & ns & ns \\
\hline Ácido úrico & 0,70 & 0,53 & 0,59 & 0,51 & 35,1 & ns & ns & ns \\
\hline Xantina e hipoxantina & 0,65 & 0,66 & 0,64 & 0,63 & 18,7 & ns & ns & ns \\
\hline Purinas totais & 7,46 & 7,60 & 8,20 & 7,88 & 20,3 & ns & ns & ns \\
\hline \multicolumn{9}{|c|}{ Purinas microbianas (mmol/dia) } \\
\hline Absorvidas & 9,8 & 10,0 & 10,8 & 10,4 & 20,3 & ns & ns & ns \\
\hline \multicolumn{9}{|c|}{ Derivados de purinas (\% das purinas totais) } \\
\hline Alantoína ${ }^{2}$ & 81,1 & 84,0 & 84,7 & 84,9 & 3,8 & $*$ & ns & ns \\
\hline Ácido úrico ${ }^{3}$ & 9,3 & 7,0 & 7,6 & 6,6 & 25,9 & $* *$ & ns & ns \\
\hline Xantina e hipoxantina & 9,6 & 9,0 & 8,0 & 8,5 & 31,3 & ns & ns & ns \\
\hline \multicolumn{9}{|c|}{ Produção microbiana (g/dia) } \\
\hline N-microbiano & 5,4 & 5,5 & 6,0 & 5,7 & 20,3 & ns & ns & ns \\
\hline PB-microbiana & 33,9 & 34,5 & 37,2 & 35,7 & 20,2 & ns & ns & ns \\
\hline \multicolumn{9}{|c|}{ Eficiência microbiana } \\
\hline g PB/kg NDT & 62,8 & 63,2 & 66,7 & 55,8 & 18,2 & ns & ns & ns \\
\hline
\end{tabular}

1 ns = não-significativo $(\mathrm{P}>0,05) ; *$ significativo a 0,05 de probabilidade; e $* *$ significativo a 0,01 de probabilidade. $\mathrm{CV}=$ coeficiente de variação, $\mathrm{N}$-microbiano $=$ nitrogênio microbiano, PB-microbiana = proteína microbiana e g PB/kg NDT = gramas de proteína bruta por quilograma de nutrientes digestíveis totais consumido. 


\section{Conclusões}

O nitrogênio retido, as concentrações de nitrogênio uréico na urina e no plasma e as excreções de ureia na urina de caprinos não são influenciados pelo uso do óxido de cálcio na cana-de-açúcar. A utilização de cana-de-açúcar tratada com óxido de cálcio, em dietas para caprinos em crescimento, não altera a excreção de derivados de purinas e nem melhora a síntese de compostos nitrogenados e a eficiência microbiana.

\section{Referências}

BARTON, B.A.; ROSARIO, H.A.; ANDRESON, G.M. et al. Effect of dietary crude protein, breed, parity, and health status on the fertility of dairy cows. Journal of Dairy Science, v.79, n.12, p.2225-2236, 1996.

BELENGUER, A.; YAÑEZ, D.; BALCELLS, J. et al. Urinary excretion of purine derivatives and prediction of rumen microbial outflow in goats. Livestock Production Science, v.77, n.3, p.127-135, 2002.

BRANCO, A.T.; ZEOULA, L.M.; BUMBIERIS, V.H. Farinha de penas hidrolisada em dietas de ovinos. Revista Brasileira de Zootecnia, v.32, n.6, p.1454-1460, 2003.

BUTLER, W.R. Symposium: optimizing protein nutrition for reproduction and lactation. Journal of Dairy Science, v.81, n.9, p.2533-2539, 1998.

BUTLER, W.R.; CALAMAN, J.J.; BEAM, S.W. Plasma and milk urea nitrogen in relation to pregnancy rate in lactating dairy cattle. Journal of Animal Science, v.74, n.4, p.858-865, 1996.

CASALI, A.O.; DETMANN, E.; VALADARES FILHO, S.C. et al. Influência do tempo de incubação e do tamanho de partículas sobre os teores de compostos indigestíveis em alimentos e fezes bovinas obtidos por procedimentos in situ. Revista Brasileira de Zootecnia, v.37, n.2, p.335-342, 2008.

CHEN, X.B.; GOMES, M.J. Estimation of microbial protein supply to sheep and cattle based on urinary excretion of purine derivatives - an overview of technical details. Bucksburnd: Rowett Research Institute/International Feed Research Unit, 1992. 21p. (Occasional publication).

DETMANN, E.; QUEIROZ, A.C.; CECON, P.R. et al. Consumo de fibra em detergente neutro por bovinos em confinamento. Revista Brasileira de Zootecnia, v.32, n.6, p.1763-1777, 2003.

DETMANN, E.; VALADARES FILHO, S.C.; HENRIQUES, L.T. et al. Reparametrização do modelo baseado na lei de superfície para predição da fração digestível da fibra em detergente neutro em condições brasileiras. Revista Brasileira de Zootecnia, v.36, n.1, p.115-164, 2007.

FONSECA, C.E.M.; VALADARES, R.F.D.; VALADARES FILHO, S.C. et al. Estimativa da produção microbiana em cabras alimentadas com diferentes teores de proteína na dieta. Revista Brasileira de Zootecnia, v.35, n.3, p.1169-1177, 2006.

HALL, M.B. Challenges with non-fiber carbohydrate methods. Journal of Animal Science, v.81, n.12, p.3226-3232, 2003.

KOZLOSKI, G.V. Bioquímica dos ruminantes. Santa Maria: UFSM, 2002. 140p.

LENINGHeR, A.L.; NELSON, D.L.; COX, M.M. Princípios de bioquímica. 2.ed. São Paulo: Sarvier, 1995. 839p.

LICITRA, G.; HERNANDEZ, T.M.; VAN SOEST, P.J. Standardization of procedures for nitrogen fracionation of ruminant feed. Animal Feed Science Technological, v.57, n.4, p.347-358, 1996
MAGALHÃES, K.A.; VALADARES FILHO, S.C.; VALADARES, R.F.D. et al. Produção de proteína microbiana, concentração plasmática de uréia e excreções de uréia em novilhos alimentados com diferentes níveis de uréia ou casca de algodão. Revista Brasileira de Zootecnia, v.34, n.4, p.1400-1407, 2005.

MENDONÇA, S.S.; CAMPOS, J.M.S.; VALADARES FILHO, S.C. et al. Consumo, digestibilidade aparente, produção e composição do leite e variáveis ruminais em vacas leiteiras alimentadas com dietas à base de cana-de-açúcar. Revista Brasileira de Zootecnia, v.33, n.2, p.481-492, 2004a.

MENDONÇA, S.S.; CAMPOS, J.M.S.; VALADARES FILHO, S.C. et al. Balanço de compostos nitrogenados, produção de proteína microbiana e concentração plasmática de uréia em vacas leiteiras alimentadas com dietas à base de cana-de-açúcar. Revista Brasileira de Zootecnia, v.33, n.2, p.493-503, 2004b.

MERTENS, D.R. Gravimetric determination of amylase-treated neutral detergent fiber in feeds with refluxing in beakers or crucibles: collaborative study. Journal of AOAC International, v.85, n.6, p.1217-1240, 2002.

MORAES, S.A. Subprodutos da agroindústria e indicadores externos de digestibilidade aparente em caprinos. 2007. 46f. Tese (Doutorado em Ciência Animal) - Escola de Veterinária da Universidade Federal de Minas Gerais, Belo Horizonte.

MOURO, G.F.; BRANCO, A.F.; HARMON, D.L. et al. Fontes de carboidratos e porcentagem de volumosos em dietas para ovinos: balanço de nitrogênio, digestibilidade e fluxo portal de nutrientes. Revista Brasileira de Zootecnia, v.36, n.2, p.489-498, 2007.

NATIONAL RESEARCH COUNCIL - NRC. Nutrient requirements of dairy cattle. 7.ed. Washington: National Academy Press, 2001. 450p.

NATIONAL RESEARCH COUNCIL - NRC. Nutrient requirements of small ruminants. Washington: National Academy Press, 2006, 362p.

OLIVEIRA, A.S.; VALADARES, R.F.D.; VALADARES FILHO, S.C. et al. Produção de proteína microbiana e estimativas das excreções de derivados de purinas e de uréia em vacas lactantes alimentadas com rações isoprotéicas contendo diferentes níveis de compostos nitrogenados não-protéicos. Revista Brasileira de Zootecnia, v.30, n.5, p.1621-1629, 2001.

PAULINO, M.F.; DETMANN, E.; VALADARES FILHO. S.C. Suplementação animal em pasto: energética ou protéica? In: SIMPÓSIO SOBRE MANEJO ESTRATÉGICO DA PASTAGEM, 3., 2006, Viçosa, MG Anais... Viçosa, MG: SIMFOR, 2006. p.359-392.

PINA, D.S.; VALADARES FILHO, S.C.; VALADARES, R.F.D. et al. Síntese de proteína microbiana e concentrações de uréia em vacas alimentadas com diferentes fontes de proteína. Revista Brasileira de Zootecnia, v.35, n.4, p.1552-1559, 2006.

PRADO, I.N.; MOREIRA, F.B. Suplementação de bovinos no pasto e alimentos usados na bovinocultura. Maringá: UEM, 2002. 162p.

PUCHALA, R., KULASEK, G.W. Estimation of microbial protein flow from the rumen of sheep using microbial nucleic acid and excretion of purine derivatives. Canadian Journal of Animal Science, v.72, n.4, p.821-830, 1992.

RUAS, J.R.M.; TORRES, C.A.A.; BORGES, L.E. et al. Efeito da suplementação protéica a pasto sobre eficiência reprodutiva e concentração sanguínea de colesterol, glicose e uréia em vacas Nelore. Revista Brasileira de Zootecnia, v.29, n.6, p.2043-2050, 2000.

SILVA, D.J., QUEIROZ, A.C. Análise de alimentos: métodos químicos e biológicos. Viçosa, MG: UFV, 2002. 235p.

SNIFFEN, C.J.; O'CONNOR, D.J.; Van SOEST, P.J. et al. A net carbohydrate and protein system for evaluating cattle diets: carbohydrate and protein availability. Journal of Animal Science, v.70, n.12, p.3562-3577, 1992. 
SOTO-NAVARRO, S.A.; GOETTSCH A.L.; SAHLU, T. et al. Effects of ruminally degraded nitrogen source and level in a high concentrate diet on site of digestion in yearling Boer $\mathrm{x}$ Spanish wether goats. Small Ruminant Research, v.50, n.1, p.117-128, 2003.

STATISTICAL ANALYSES SYSTEM - SAS. SAS user's guide. Cary: 1999. v.8, 295p.

VALADARES, R.F.D.; BRODERICK, G.A.; VALADARES FILHO, S.C. et al. Effect of replacing alfalfa with high moisture corn on ruminal protein synthesis estimated from excretion of total purine derivatives. Journal of Dairy Science, v.82, n.12, p.2686-2696, 1999.

WEISS, W.P. Energy prediction equations for ruminant feeds. In: CORNELL NUTRITION CONFERENCE FOR FEED MANUfacturers, 61., 1999, Ithaca. Proceedings... Ithaca: Cornell University, 1999. p.176-185.

YU, P.; EGAN, A.R.; BOON-EK, L. et al. Purine derivative excretion and ruminal microbial yield in growing lambs fed raw and dry roasted legume seeds as protein supplements. Animal Feed Science and Technology, v.95, n.1, p.33-48, 2002. 